\title{
РАЗВИТИЕ РЕГИОНАЛЬНОГО ТРАНСПОРТНО-ЛОГИСТИЧЕСКОГО КЛАСТЕРА: НА ПРИМЕРЕ РЕСПУБЛИКИ БЕЛАРУСЬ
}

\author{
Ю.В. МЕЛЕШКО \\ магистр экономических наук, главный инспектор Минской региональной таможни, \\ г. Минск
}

Аннотация

В статье изложены основные теоретические подходы к понятию «кластер», выделены и рассмотрены его основные признаки. Изучены свойства транспортно-логистического кластера как кластера сферы услуг, определены особенности его формирования и развития на территории Республики Беларусь. Рассмотрены дополнительные конкурентные преимущества, которые наравне с использованием основных факторных условий позволят занять нашей стране место на международном транспортно-логистическом рынке.

Abstract

This article presents the main theoretical approaches to the concept of "cluster", highlights and discusses its main features. The properties of the transport and logistics cluster as a cluster of services are studied, the peculiarities of its formation and development within the territory of the Republic of Belarus are determined. Additional competitive advantages, which, alongside with the use of basic factor conditions will allow our country to take place in the international transport and logistics market.

\section{ВВЕДЕНИЕ}

Структурные сдвиги в мировой экономике характеризуются снижением доли сферы сельского хозяйства и индустриального сектора, повышением значения информации, знаний, новейших технологических разработок в индустриальном секторе, увеличением удельного веса третичного сектора - сферы услуг. Технический прогресс способствует росту производительности труда и автоматизации производственных процессов, что в свою очередь приводит к высвобождению рабочей силы из сферы промышленности и росту домашних доходов, в результате происходит увеличение доли сферы услуг во внутреннем валовом продукте и занятых в данной сфере. Такая тенденция характерна как для развитых стан, так и для стран с переходной экономикой, и Республика Беларусь не является исключением. В структуре валового внутреннего продукта Беларуси сфера услуг составила в первом полугодии 2014 г. 48,1\% [1]. Наиболее весомыми в сфере услуг нашей страны являются секция «Торговля, ремонт автомобилей, бытовых изделий и предметов личного пользования», секция «Транспорт и связь» и секция «Операции с недвижимым имуществом, аренда и предоставление услуг потребителям», доля которых в структуре валовой добавленной стоимости сферы услуг составляет соответственно $30,8 \%, 18,4 \%$ и $12,7 \%$ [1].

На фоне глобализации национальные экономики перестают быть обособленными, а входят в единую систему мирового хозяйства, в результате экономики стран находятся в тесной взаимозависимости, базирующейся на двух процессах, противоположных по направлению, но являющихся непосредственным результатом глобализации: транснационализации и регионализации. С образование единого международного рынка появляется необходимость в использовании логистических подходов с целью объединения всех стадий производства и сбыта в единый процесс движения и трансформации товара на основе материального и информационного потоков. Внедрение логистических подходов в сфере обращения товаров позволяет сократить запасы продукции, снизить транспортные расходы, уменьшить количество грузовых операций, увеличить скорость движения товаров, что приводит к значительной экономии на транзакционных издержках.

В современных условиях всевозрастающей международной конкуренции для завоевания и сохранения ниши на международном рынке, а также обеспечения устойчивого экономического развития странам необходимо максимально эффективно использовать свою особенную социально-экономическую среду. Одним из преимуществ Республики Беларусь является геоэкономическое положение: находясь на пересечении путей, соединяющих товарные ранки стран Евросоюза с Россией, Казахстаном, Китаем и странами Юго-Восточной Азии, Беларусь обладает значительным транзитным потенциалом, используемым на сегодняшний день не в полной мере. В результате реализации Государственной программы развития транзитного потенциала на 2011-2015 гг., в соответствии с которой предусматривается совершенствование законодательства в области обеспечения транзита, расширение финансовых коридоров, научноисследовательские работы, реконструкция и модернизация транзитной инфраструктуры, объем доходов, полученных от транзита грузов, увеличился в 2013 г. на 4,5\% по сравнению с 2012 г. (3137,1 млн. долл. США и 3003 млн. долл. США соответственно) [2]. Таким образом, основываясь на мировых тенденциях развития экономики, а также учитывая геоэкономическое положение нашей страны, для Республики Беларусь становится особенно актуальным развитие транспортно-логистического рынка как для собственного потребления, так и для экспорта транспортно-логистических услуг.

Инновационным подходом к управлению экономическим развитием в условиях регионализации является кластерный подход, базирующийся на концентрации на определенной территории значительного количества производи- 
телей, участвующих в цепочке создания добавленной стоимости, за счет взаимодействия которых достигается синергетический эффект.

\section{РЕЗУЛЬТАТЫ И ИХ ИССЛЕДОВАНИЕ}

Понятие «кластер» относительно новое, его ввел М. Портер в 90-х годах прошлого века при изучении вопроса международных конкурентных преимуществ компании [3]. Хотя предпосылки возникновения теории кластеров появились еще раньше: в работе А. Маршалла «Принципы политической экономии» [4], один из раздела которой был посвящен феноменам особых промышленных регионов.

Исследование кластеров на постсоветском пространстве активизировалось только последние несколько лет благодаря работам таких авторов, как И.Г. Меньшенина, Л.М. Капустина [5], Л.С. Марков [6], Г.А. Яшева [7], Пятинкин С.Ф. [8]. Но стоит отметить, что еще многие проблемы остаются не до конца раскрытыми, в том числе последовательность организации кластеров в экономике регионов, институциональное обеспечение кластерного подхода. Также необходимо принять во внимание, что основной упор при изучении явления кластеризации экономики делается на сферу производства, в то время как сфера услуг, к которой и относится транспортно-логистический рынок, остается в стороне.

Мировой опыт показывает, что кластеры чаще всего создаются в таких секторах промышленности как производство легкой промышленности, медицинского оборудования, химическая промышленность, биофармацевтика, автомобилестроение, машиностроение, пищевая промышленность, энергетика. Если говорить о кластерах услуг, то наибольшее распространение получили туристические, медицинские, образовательные, финансовые, транспортнологистические и IT-кластеры [9]. Удачным примером использования кластерного подхода в транспортнологистической сфере является Европейский союз, в котором функционирует сеть из более чем восьмидесяти транспортно-логистических кластеров, а доля транспортно-логистических услуг, оказываемых специализированными организациями, в общем обороте достигла $40 \%$ [10].

Классическое определение понятия «кластер» было дано М. Портером: «кластер - это группа географически соседствующих, взаимосвязанных компаний (поставщики, производители и др.) и связанных с ними организаций (образовательные заведения, органы государственного управления, инфраструктурные компании), действующих в определенных сферах и взаимодополняющих друг друга» $[11,389]$. М. Энрайта определял региональный кластер как «географическую агломерацию фирм, работающих в одной или нескольких родственных отраслях хозяйства» [12].

С позиции институционального подхода кластер представляет собой «область экономических возможностей рынка, где бизнес все больше расширяется в различных отраслевых сегментах: от финансов до производства и распределения» [13]. Кластер как современный экономический институт сочетает в себе систему формализованных и неформализованных отношений его участников между собой, в результате которой возникает экономия на транзакционных издержках. В качестве фактора конкурентоспособности региона выступает степень развития его институциональной структуры, и динамика развития региона зависит от особенностей институциональных связей между органами власти и конкурирующими между собой предприятиями. Кластер играет роль платформы для успешного взаимодействия всех участников кластера и решает проблему взаимодействия органов управления и бизнеса при помощи механизма государственно-частного партнерства, основанного на согласовании властных полномочий и экономических интересов, укрепления имущественных и хозяйственно-производственных связей, усиления методов мотивации и контроля над ресурсами и результатами деятельности. Взаимодействие участников кластера осуществляется в двух противоположных направлениях: конкуренция и кооперация. При этом, однако, кластерный подход изменяет привычную логику конкуренции. В традиционной конкурентной среде выигрыш одного участника означает проигрыш другого, в рамках кластера каждому хозяйствующему субъекту предоставляется возможность достижения выгод. В результате использования кластерного подхода международная конкуренция устанавливается не на уровне отдельных предприятий, а на уровне кластеров [10].

Д. Якобс в своих работах справедливо подчеркивает значимость развития в кластере горизонтальных и вертикальных отношений между отраслями промышленности, использования общих технологий, наличия лидера, а также качества сетевого взаимодействия. С этих позиций кластеры выступают альтернативой секторальному (отраслевому) подходу $[14,49]$. Объединяя в себе участников смежных и сопутствующих отраслей, которые, тем не менее, относятся к различным областям производства, кластерная политика направлена на разработку комплексных мероприятий развития региональной и национальной экономик, в то время как отраслевой подход предполагает реализацию отдельных стратегий развития по отраслям. Кластерный подход является инновационной формой управления регионами, государственные органы управления направляют свои усилия не на отдельные отрасли или организации, а на продуктивное взаимодействие элементов кластера как внутри кластера, так и с внешней средой.

По мнению некоторых экономистов, основным преимуществом кластерного развития экономики является стимулирование выработки и использования инноваций. Например, Р. Камажни разработал концепцию «инновационной среды», в которой под инновационной средой понимается «сложная сеть главным образом неформальных социальных взаимосвязей в ограниченной географической области, часто определяющих специфический внешний имидж, внутренний облик и чувство причастности, которые увеличивают локальную инновационность через синергетические и коллективные процессы обучения» [15]. Возникающие в инновационной среде специфические взаимосвязи способствуют выработке новых знаний, процессов и продуктов.

Под транспортно-логистическим кластером понимается «устойчивое взаимодействие географически сконцентрированных независимых рыночных субъектов, усилия которых направлены на поддержание полного цикла основ- 
ных и сопутствующих потоков, сквозную оптимизацию ресурсов от исходных поставщиков до конечных потребителей, реализующих логистические функции» [16]. Транспортно-логистические кластеры способствуют активизации международных транспортных коридоров, обеспечивают эффективную работу логистических цепочек, становятся центрами деловой активности в сфере транспортной логистики и могут стать точками роста для национальной экономики.

Следует выделять следующие ключевые характеристики феномена «кластер», отличающие его от остальных экономических категорий: географическая концентрация, широкий набор участников и наличие критической массы, специализация, инновационность, конкуренция и кооперация, взаимодействие участников кластера. Все указанные отличительные особенности важны в равной мере, и исключить какой-либо пункт, не потеряв при этом в понятии самого кластера, не представляется возможным. Рассмотрим каждое из названных свойств подробнее.

Первый и определяющий признак кластеров - концентрация предприятий на определенной территории. Участниками кластера являются не все предприятия, а те, что задействованы в создании добавленной стоимости конкретного товара (продуктов, услуг) или товаров определенной группы (типа). Кластер не предполагает ограниченный круг участников, в процессе развития «кластер притягивает к себе предприятия, организации и фирмы, которые кроме ключевых для кластеров бизнес-процессов привносят вспомогательные и побочные экономические процессы» [17]. Основными категориями участников кластера являются предприятия, специализирующиеся на профильных видах деятельности, которые становятся ядром кластера, поставщики товаров и услуг для основных производителей, предприятия, создающие и обслуживающие инфраструктуру кластера, научные организации, исследовательские институты и учреждения образования, некоммерческие организации, на которые возложены координирующие функции.

Существует определенный уровень территориальной концентрации предприятий, по достижению которого можно говорить о возникновении кластера. В Концепции формирования и развития инновационно-промышленных кластеров в Республике Беларусь приведен коэффициент локализации, вычисляемый на основании показателя занятости в отрасли в отдельном регионе, занятости в стране в целом, занятости в регионе в целом и занятости в отрасли в стране. Пороговым значением для формирования кластера на территории региона является значение коэффициента локализации 1,5 и более [18]. Кластеры возникают там, где все необходимы ресурсы и компетенции сосредотачиваются, достигают определенного масштаба, некоторого критического порога и приобретают ключевую роль в определенной экономической сфере с решающим и устойчивым конкурентным преимуществом над другими регионами за счет более высокой производительности, развития инноваций и новых видов бизнеса.

Транспортно-логистические кластеры включают в себя комплекс инфраструктуры и компаний, специализирующихся на хранении, сопровождении и доставке грузов и пассажиров. Участниками данного вида кластеров являются транспортные, логистические, экспедиторские, страховые компании, центры оптово-розничной торговли, ремонтносервисные предприятия, таможенные представители, учреждения профессионального образования, научные и опытно-исследовательские организации в сфере транспорта и логистики, государственные органы управления (таможенные органы, министерство транспорта и коммуникаций, местные органы управления, курирующие данный вид деятельности).

Кластер может включать в себя предприятия, относящиеся к разным отраслям промышленности (межотраслевые кластеры), которые группируются исходя из степени межотраслевой циркуляции продукции и знаний. Развитие кластера повышает взаимодействие между отраслям и, тем самым, способствуем мультипликационному эффекту. Кластеризация экономики может происходить по двум направлениям: «формирование кластеров, основанных на различных типах ограниченных ресурсов (возможностей), находящихся в настоящий момент времени в определенном регионе, и формирование кластеров в транспортной сфере, как части инфраструктуры, обеспечивающей эффективное функционирование промышленности в области обеспечения материально-техническими ресурсами и каналами распределения продукции» [19]. Транспортно-логистический кластер имеет двойственную природу: с одной стороны он выступает как инфраструктурный элемент производственного кластера, с другой - как самостоятельной кластерной организацией. Являясь особым типом кластеров, транспортно-логистический кластер способствует формированию и развитию других производственных кластеров и отраслей, продукция которых в составе своей цены включает транспортную составляющую, доля которой зачастую весьма высока. При обслуживании транзитных товаропотоков транспортно-логистический кластер выступает как самостоятельный кластер, что особенно актуально для Республики Беларусь как участницы Таможенного союза Республики Беларусь, Республики Казахстан и Российской Федерации и Евразийского экономического союза.

С точки зрения географической локализации транспортно-логистические кластеры бывают 3 категорий: портовые, пограничные и территориальные (региональные). Учитывая географическое положение Беларуси и сложившиеся товаротранспортные потоки, для нашей страны представляют интерес последние два вида [20]. Если же рассматривать формирование белорусского транспортно-логистического кластера в масштабах функционирующего Таможенного союза трех государств, то такой кластер может располагаться на всей территории Республики Беларусь, не ограничиваясь приграничными регионами. Таким образом, создание транспортно-логистичекого кластера в Беларусь целесообразно осуществлять не на региональном, а на национальном уровне, а Республика Беларусь выступает в данном случае как регион Единого экономического пространства.

На сегодняшний день применение кластерного подхода в Республике Беларусь на нормативном уровне закреплено преимущественно за развитием промышленного сектора экономики, так в рамках Программой инновационного развития Республики Беларусь на 2011-2015 годы, утвержденной Постановлением Совета Министров Республики Беларусь от 26 мая 2011 г. № 669, планируется создать химический, промышленный, автотракторостроительный, химико-текстильный и ИТ-кластеры [21]. Развитие же логистического рынка в Республике Беларусь осуществляется в со- 
ответствии с Программой развития в Республике Беларусь логистической системы на период до 2015 г., утвержденной постановлением Совета Министров №1249 от 29 августа 2008 г. Под логистической системой понимается «сложная организационно завершенная (структурированная) экономическая система, которая состоит из элементов-звеньев (транспортно- и оптово-логистических (торгово-логистических) центров), взаимосвязанных между собой и взаимодействующих посредством информационного обмена в целях достижения эффективного управления цепями поставок товаров и грузов, с участием республиканских и местных органов государственного управления, заинтересованных организаций, располагающих транспортными, складскими, экспедиторскими, информационными, финансовыми, сертификационными, страховыми и производственными структурами» [22]. Основой формирования логистической системы являются транспортно-логистические центры, представляющие широкий спектр не только логистических, но и сопутствующих услуг (банковские, страховые, услуги по бытовому обслуживанию). В качестве логистической системы можно рассматривать промышленные предприятия, объединения, комплексы, торговые фирмы, экономические регионы страны, инфраструктуру страны (транспорт) и др. В сравнении с логистической системой транспортнологистический кластер предполагает широкий состав участников, конкурирующих между собой, но преследующих общую цель эффективного обслуживания экспортных, импортных и транзитных потоков. Выстраивающиеся в транспортно-логистическом кластере связи между участниками носят преимущественно горизонтальный характер, в то время как в логистической системе - вертикальный. Состав участников и структура кластера не являются стабильными и определяются набором потребностей субъектов хозяйствования на данном рынке, кластерообразующим предприятием (несколькими предприятиями), потенциалом развития, влиянием факторов внешней среды.

Кластерообразующие предприятия задают определенную специализацию кластера, выражающуюся в производстве конкретного товара. В силу широкого состава участников кластер может специализироваться на производстве не одного, а группы товаров, относящихся, однако, к одному типу либо являющихся продукцией смежных, сопутствующих отраслей. В процессе развития кластера его специализация может меняться и продукт, изначально производящийся как дополнительный (необходимый элемент основного), становится ключевым. Кроме того, завоевав конкурентную позицию на международном рынке, такой продукт может стать образующим для нового кластер. Основным товаром транспортно-логистического кластера являются услуги в сфере транспортной логистики, направленные на удовлетворение требования рынка в поставке товаров и услуг с наименьшими издержками, оптимизацию производственного процесса, обеспечение эффективной работы логистических цепочек.

Ключевым признаком кластера является наличие системно развивающихся связей, кооперации и конкуренции между его участниками. Постоянное взаимодействие способствует формальному и неформальному обмену информацией, знаниями, сотрудничеству между предприятиями с взаимодополняющими видами деятельности, функциями, активами и профессиональными навыками. При таких условиях успех одной фирмы будет способствовать развитию другой, за счет эффекта масштаба повышается эффективность деятельности как каждой отдельной фирмы, так и кластера вообще. Все предприятия в кластере находятся в тесных широкоформатных разносторонних взаимосвязях, то есть, связи выстраиваются не только за счет непосредственных целевых контактов, но и зачастую переходят на уровень социальных связей (социальный капитал). Как считают некоторые авторы, экономический рост в кластере достигается за счет согласования интересов участников регионального сообщества, установления партнерских отношений между субъектами кластера благодаря активному включению государственных структур в его функционирование, например через механизмы государственно-частного партнерства, создания социально-предпринимательских корпораций на территории кластера [9]. По нашему мнению, в данном случае кластер как экономический феномен идеализируется, в результате исчезают реальные противоречия и некоторые рыночные отношения (конкуренция), следовательно, такой подход не является универсальным. Осуществляя свою деятельность в рамках кластера его участники конкурируют между собой, к примеру, за более благоприятные условия доступа к ограниченным ресурсам, за внимание покупателей на внутреннем рынке, за получение государственной поддержки, конкуренция существует также между покупателем и продавцом за лучшие условия сделки. Таким образом, кластер представляет собой оптимальную форму организации предприятий (фирм), внутри которой происходит как конкурентная борьба, так и сотрудничество.

Важной отличительной чертой кластера является инновационная ориентированность участников кластера. Успех функционирования кластера напрямую зависит от инновационности товаров и услуг, являющихся продуктами кластера. При этом использование не только продуктовых, но и технологических, менеджментовых, маркетинговых и иных общественно-функциональных инноваций создает дополнительные конкурентные преимущества для производителя на внутреннем рынке. При наличии внутренней конкурентной среды использование инноваций становится необходимым условием существования предприятия, что, в конечном счете, повышает общую конкурентоспособность как региона, так и страны в целом. Кластер позволяет создать эффективную системную организацию научных и исследовательских разработок, качественное и своевременное обеспечение научной сферы и технологических инноваций, успешную коммерциализацию и диффузию выработанных инноваций. В целях обеспечения успешного функционирования транспортно-логистического кластера активно используется инновационный менеджмент как инструмент логистизации всех сопряженных бизнес-процессов, с помощью которого планомерно реализуются нововведения технико-технологического, проектно-конструкторского и организационно-экономического характера.

В условиях функционирования Таможенного союза и Единого экономического пространства белорусскому транспортно-логистического кластеру придется конкурировать с соседними регионами, в частности Москва, СанктПетербург, которые также намерены развиваться в данном направлении. При этом имеющиеся условия создания транспортно-логистического кластера (выгодное геоэкономическое положение, проходящие международные транспортные коридоры) в этих регионах принципиально не отличается от белорусских. В связи с этим для перераспреде- 
ления транзитных потоков, проходящих по территории стран-участниц ЕЭП, на территорию Беларуси следует создать дополнительные конкурентные преимущества.

М. Портером были выделены следующие источники конкурентных преимуществ: конкурентные факторы, которые нужны для успешной конкуренции в данной отрасли (инфраструктура, квалифицированная рабочая сила), спрос на продукцию кластера на внутреннем рынке, наличие конкурентоспособных на мировом рынке родственных или поддерживающих отраслей, стратегия фирмы (ее структура, способ управление, административные требования, конкуренция на внутреннем рынке). Названные выше четыре фактора составляют «ромб конкуренции» - «систему, компоненты которой взаимно усиливаются» $[11,93]$. Рассмотрим подробнее стороны указанного ромба в контексте развития транспортно-логистического кластера.

В качестве факторов производства для любого кластера выступают природные ресурсы (качество и стоимость, доступность ресурсов), трудовые ресурсы (уровень профессиональной подготовки, обеспеченность кадрами), информационные ресурсы, инфраструктура. Применительно к транспортно-логистическим кластерам основными факторами являются геоэкономическое расположение региона, стоит, однако, учитывать, что благодаря научно-техническому прогрессу конфигурация грузопотоков в современной мировой экономике легко меняется в зависимости от политической и экономической обстановки. Немаловажную роль для транспортно-логистического кластера играет и имеющаяся инфраструктура (транспортная сеть, качество подвижного состава, качество дорожного покрытия, развитый придорожный сервис, простота административных процедур (допуск транспортного средства, оплата за проезд по платным дорогам), наличие мультимодальных транспортно-логистических центров). Территорию Республики Беларусь пересекают 2 трансъевропейских транспортных коридора, определенных по международной классификации под номером II (Запад - Восток) и под номером IX (Север - Юг) с ответвлением IX В, проходящих через города Брест, Витебск, Гомель, Минск. На сегодняшний день инфраструктура в Беларуси не отвечает в полной мере мировым транспортнологистическим стандартам, однако реализуется ряд мероприятий, целью которых является реконструкция, совершенствование и развитие транспортной инфраструктуры. В частности, на постоянной основе поэтапно обновляется подвижной состав, проводится реконструкция дорог. С 2013 г. на территории Беларуси функционирует национальная электронная система взимания платы за проезд по платным дорогам, призванная в будущем решить проблему финансирования реконструкции транспортной инфраструктуры. С 2013 г. в Беларуси действуют 21 логистический центр различной функциональности. К концу 2014 г. планируется открыть еще 9 [23].

Наличие спроса на внутреннем рынке приводит к стремлению производителей повысить качество своего товара. Местный покупатель, как правило, более требовательный и разборчивый, что заставляет предприятия вводить новации быстрее и добиваться конкурентных преимуществ. Кроме того потребности местных покупателей доходят до субъектов хозяйствования раньше и точнее, чем до международных конкурентов. При наличии достаточно высокого уровня спроса предприятие может выиграть, используя эффект масштаба, а также высокий спрос будет привлекать инвестиции [24, 121-122]. Условия местного спроса для участников транспортно-логистического кластера зависят от ареала его действия, зачастую распространяющегося на другие регионы. Особенно при обслуживании транзитного грузопотока. В связи с этим большое значение приобретает информационная инфраструктура, способная обеспечить быструю передачу данных. Потребность в транспортно-логистических услугах концентрируется, как правило, в индустриальных агломерациях.

Положительное влияние на динамику спроса на внутреннем рынке может оказать и развитие конкурентоспособных на мировом рынке экспортеров, нуждающихся в логистических услугах. Однако в настоящее время все более ли менее крупные экспортеры удовлетворяют потребность в логистических услугах собственными силами, так ими производится примерно 70\% всего объема логистических операций [25]. Все постсоветские страны, и Республика Беларусь не исключение, входят в число стран с высоким уровнем логистических издержек (основные затраты приходятся на управление запасами, складскую и транспортную логистику). Причиной этому является сложившееся и ставшее традиционным отношение к логистике как к вспомогательному производству по остаточному принципу. Решением проблемы может стать логистический аутсорсинга, суть которого заключается в отсутствии необходимости использования собственных ресурсов для организации логистических операций и их передаче внешнему партнеру. Таким образом компания избавляется от неэффективных и непрофильных бизнес-процессов, что позволит ей оптимизировать структуру добавленной стоимости и высвободить капитал для развития основных видов деятельности.

Успешность родственных и поддерживающих отраслей на международном рынке положительно скажется на конкурентоспособности кластера. При этом под родственными понимаются такие отрасли, в которых предприятия могут осуществлять взаимодействие между собой в процессе формирование цепочки ценностей, а также отрасли, имеющие дело с взаимодополняющими продуктами, такими как компьютеры или программное обеспечение. В таких случаях взаимодействие между предприятиями данных отраслей происходит в сфере развития технологий, производства, распространение маркетинга или сервиса $[24,126]$. Для транспортно-логистического кластера родственными отраслями являются производство транспортного оборудования, энергетика, информационные технологии, связь, металлургия и строительство. К поддерживающим видам деятельности относятся услуги, образование, консалтинг, таможенные услуги.

Немаловажное значение для успешного функционирования кластера имеет выбранная стратегия управления и структура предприятия. Ни одна из систем управления не может подходить всем компаниям. Для предприятия, осуществляющего свою деятельность в области транспортной логистики, наилучшим будет выбор более гибких и демократических структур, способных реагировать на быстрые изменения рынка. Для транспортно-логистического кластера предпочтительным являются развитие горизонтальных связей между участниками, так как вертикальные связи предполагают подотчетность вышестоящей организации, которой может являться и государственный орган управле- 
ния, жесткую управленческую структуру, что не может обеспечить необходимую в сфере транспортной логистики поливариантность и скорость принятия решений. Ценность кластера не столько в комплексности, сколько в наличии внутренней конкуренции, чем он и отличается от картелей, холдингов, промышленных групп.

Кластер, как правило, не является юридическим лицом, однако для координации действий, выработке общих стратегий, обеспечения сотрудничества и регулирования внутренней конкуренции, взаимодействия с органами власти в кластере создается центр управления. В мировой практике предпочтение отдается ассоциации. Ассоциация выступает инициатором создания кластеров в регионе, оказывает помощь в разработке стратегии конкурентоспособности, предоставляет информацию о требованиях покупателей, об уровне конкуренции, создает и поддерживает связи между участниками кластера, взаимодействует с местными органами власти и правительством страны [26]. Учредителями ассоциации производителей могут быть базовое (отраслевое) высшее учебное заведение, научно-исследовательская организация, исполнительный комитет местного органа государственного управления, крупные отраслевые предприятия. Желающие, уплачивая вступительные и членские взносы, становятся членами ассоциации (в добровольном порядке). Это дает им право получать услуги ассоциации в области развития образования, активизации инноваций, совершенствования маркетинга и другие бесплатно или по льготным тарифам [27]. Важно отметить, что все указанные выше факторы находятся во взаимозависимости и влияют друг на друга, создавая особую, уникальную социальноэкономическую среду. Успех компаний кластера, основанный только лишь на одном-двух факторах, будет недолгим.

\section{ВЫВОДЫ}

Таким образом, следуя мировым тенденциям, направленным на увеличение доли сферы услуг в структуре национальной экономики, а также с учетом геоэкономического положения нашей страны, Республика Беларусь уделяет особое внимание развитию транспортно-логистического рынка, которое на данный момент осуществляется путем создания логистической системы, однако, на наш взгляд, более эффективным будет использование кластерного подхода, представляющего собой инновационную форму управления экономическим развитие регионов. Транспортнологистический кластер в Республике Беларусь, являясь кластером в сфере услуг, имеет двойственную природу, будет выступать с одной стороны как элемент инфраструктуры промышленности, с другой - как самостоятельный кластер, деятельность участников которого будет направлена, в первую очередь, на обслуживание транзитных грузопотоков. Благодаря тому, что в состав транспортно-логистического кластера входит широкий круг участников, состав которых определяется в зависимости от потребностей рынка и способен быстро меняться, специализирующихся на хранении, сопровождении и доставке грузов и пассажиров, оказывающих дополнительные страховые, финансовые, ремонтносервисные, таможенные и иные услуги, сконцентрированных на одной территории (для Республики Беларусь - на территории всей страны), взаимодействующих между собой на постоянной основе в форме кооперации и конкуренции, что способствует выработке инноваций, его создание на территории Республики Беларусь позволит обеспечить наиболее эффективное обслуживание грузопотоков, усовершенствовать процесс управления логистическими услугами, повысить транзитный потенциал страны. Положительное влияние на процесс образования транспортнологистического кластера окажет дальнейшее совершенствование транспортной инфраструктуры на территории Республики Беларусь, повышение спроса на транспортно-логистические услуги на внутреннем рынке (например, путем расширения применения аутсорсинга), успешного развития родственных (связь, производство транспортных средств) и поддерживающих (консалтинг, образование, таможенные услуги) отраслей, выбор гибкой институциональной формы кластера с преимущественно горизонтальными связями между участниками, например, создание центра управления кластером в форме ассоциации.

\section{СПИСОК ЛИТЕРАТУРЫ:}

1. Худякова И.В. Сфера услуг / Экономический бюллетень НИЭИ Министерства экономики Республики Беларусь. - 2014. - №8. - С. 37-41.

2. Жук, И.В. Миленький В.С. Транзитный потенциал Беларуси: планы и реальности/И.В. Жук, В.С. Миленький//Белорусский экономический журнал. - 2013. - №2. - С.97-115.

3. Porter, M. E. The Competitive Advantage of Nations, London, Macmillan. 1990.

4. Маршалл А. /Принципы политической экономии. / А. Маршалл. - В 3-х томах. Т.1. - М.: Прогресс, 1983. $416 \mathrm{c}$.

5. Меньшенина И.Г. Кластерообразование в региональной экономике: монография / И.Г. Меньшенина, Л.М. Капустина; Федер. агентство по образованию, Урал. гос. экон. ун-т. - Екатеринбург: Изд-во Урал. гос. экон. ун-та, 2008. - 154 c.

6. Марков, Л.С. Кластеры: формализация взаимосвязей в неформальных производственных структурах / Л.С. Марков, М.А. Ягольницер. - Новосибирск: ИЭООП СО РАН, 2006. - 194 с.

7. Яшева, Г. А. Кластерная концепция повышения конкурентоспособности предприятий в контексте сетевого сотрудничества и государственно-частного партнерства: монография / Г.А. Яшева. - Витебск: УО «ВГТУ», 200-. - 373 c.

8. Пятинкин, С.Ф. Развитие кластеров: сущность, актуальные подходы, зарубежный опыт / С.Ф. Пятинкин, Т.П Быкова. - Минск: Тиссей, 2008. - 72 с.

9. Комарова, И.И. Транспортно-логистические кластеры как механизм развития транспортных коридоров / И.И. Комарова // Современные производственные силы. - 2014. - №2. - С. 44-50. 
10. Усачев, Е.Е. Методические основы кластерообразования в транспортной сфере / Е.Е. Усачев // Известия Тульского государственного университета. Экономика и юридические науки. - 2014. - №1-1. - С.43-50.

11. Портер М. Е / Конкуренция / М.Е. Портер. - М.: Вильямс, 2010. - 592 с.

12. Enrigt M.J. Why Clusters are the Way to Win the Game? // World Link. 1995. №5. July-August. P. 24-25.

13. Yossi Sheffi. Diving Growth and Employment Through Logistics // The World Financial Review. September - October. 2012.

14. Авакян, Г.Л. Региональный банковский кластер / Г.Л. Авагян, М.Ю. Саитова. - Москва: Магистр: Инфа-М, 2012. -223 c.

15. Camagni, R. Local «milieu», uncertainty and innovation networks: Towards a new dynamic theory of economic space. // Camagni. R. (ed.) Innovation networks: Spatial perspectives. London.1991.

16. Савенкова Т.И. Инновационное развитие в сфере транспортно-логистических услуг / Т.И. Савенкова // Инновационное развитие экономики. - 2014. - №3 (20). - С.9-15.

17. Андросик Ю.Н. Формирование состава и структуры кластера в мебельной промышленности Республики Беларусь / Ю.Н. Андросик // Экономика и управление. - 1013. - №4. - С.54-59.

18. Об утверждении концепции формирования и развития инновационно-промышленных кластеров в Республике Беларусь и мероприятий по ее реализации: Постановление Совета Министров Республики Бкеларусь от 16.01.2014 №27// Консультант Плюс: Беларусь. Технология 3000 [Электронный ресурс] / ООО «ЮрСпектр», Нац. центр правовой информ.Респ. Беларусь. - Минск, 2014.

19. Даутхаджиева М.Х. Кластеризация экономики как фактор повышения уровня регионального развития / M.Х. Даутхаджиева // Terra Econmicus. - 2010. - Том 8. - №4 (часть 3). - С.185-187.

20. Смирнов И.Г. Процессы транспортно-логистической кластеризации в Европейском союзе и Украине: региональный аспект / И.Г. Смирнов // Псковский региональный журнал. - 2013. - №15. - С.66-75.

21. О государственной программе инновационного развития Республики Беларусь на 2011-2015 год: Постановление Совета Министров Республики Беларусь от 26 мая 2011 г. № 669 // Консультант Плюс: Беларусь. Технология 3000 [Электронный ресурс] / ООО «ЮрСпектр», Нац. центр правовой информ.Респ. Беларусь. - Минск, 2014.

22. О программе развития логистической системы Республики Беларусь на период до 2015 года: Постановление Совета МинистровРесп. Беларусь от 29 авг. 2008 г. № 1249 // Консультант Плюс: Беларусь. Технология 3000 [Электронный ресурс] / ООО «ЮрСпектр», Нац. центр правовой информ. Респ. Беларусь. - Минск, 2014.

23. Перечень логистических центров Республики Беларусь // Министерство транспорта и коммуникаций Республики Беларусь. - Режим доступа: http://mintrans.gov.by/rus/translogistic_306/translogistic 004/ [Электронный ресурс]. - Дата доступа: 25.10.2014.

24. Портер, М.Е. / Международная конкуренция = The Competitive Advantage of Nations/ Пер. С англ. И.В. Кавсюка и др. - М.: Международные отношения, 1993. - 896 с.

25. Транспортные перспективы Республики Беларусь в рамках ЕЭС // Компас экспедитора и перевозчика. 2013 - №1. - С. 18-22.

26. Инновационные кластеры и структурные изменения в российской экономике: отчет о НИР (заключ.) / ГУ Высшая школа экономики: рук. Темы С.В. Голованова. - М., 2010. - 145 с.

27. Элларян, А. Проблемы развития транспортно-логистических кластеров/ А. Элларян // Финансовая жизнь. 2012. - №4. - C.60-63.

Статья поступила в редакиию 29 мая 2015 года. 